\title{
A dinâmica da atenção governamental sobre as políticas de saúde no Brasil: equilíbrio e pontuações nas primeiras décadas pós- redemocratização (1986-2003)
}

\section{The dynamics of government attention on health policies in Brazil: balance and punctuation in the first decades after re-democratization (1986-2003)}

Felipe Brasila

(1) https://orcid.org/0000-0001-7282-0110 E-mail: fbrasil.ppøgmail.com

\section{Ana Cláudia Capella ${ }^{a}$}

(1) https://orcid.org/0000-0002-1423-898X

E-mail: acapellaळterra.com.br

anniversidade Estadual "Júlio de Mesquita Filho". Araraquara, SP, Brasil.

\section{Correspondência}

Felipe Brasil

Rod. Araraquara-Jaú, km I, Machados. Araraquara, SP, Brasil. CEP 14800-901.

\section{Resumo}

Este trabalho tem o objetivo central de mapear e analisar a atenção de alguns atores e instituições sobre as políticas de saúde no Brasil entre 1986 e 2003. Esse modelo de pesquisa sobre agenda governamental é conhecido sob o termo "dinâmica de políticas" (policy dynamics) e analisa o processo de mudança de políticas públicas por meio da entrada e saída de temas nas prioridades dos policymakers. Mais de $10 \mathrm{mil}$ dados, advindos de cinco fontes distintas (mensagens ao Congresso, produção legislativa, orçamento anual aprovado, Constituição Federal de 1988 e atas das conferências nacionais de saúde), foram selecionados e analisados de forma a identificar a atenção desses atores a temas específicos sobre a política de saúde. As análises de frequência, em perspectiva longitudinal e transversal, são feitas a partir de um grande conjunto de dados que refletem a atenção governamental ao longo das primeiras décadas pós-redemocratização do Brasil e permitem observar manutenções e mudanças nas políticas de saúde. Como resultado, foi possível identificar permanência da atenção governamental sobre as políticas de saúde ao longo de todo o período analisado, mostrando permanente e constante grau de atenção a essa política setorial. Do ponto de vista da dinâmica, foram identificadas manutenções, ajustes discretos e incrementais na política de saúde na maior parte do tempo, mas também foram pontuados momentos de grandes transformações ao longo do período.

Palavras-chave: Políticas Públicas; Agenda Governamental; Políticas de Saúde; Dinâmica de Políticas. 
This paper aims to map and analyze the attention of some actors and institutions on health policies in Brazil between 1986 and 2003. This model of research on the government agenda is known under the term of policy dynamics and analyzes the process of changing public policies by the entering and exiting of topics in the priorities of policymakers. More than 10,00o data from five different sources (messages to the Congress, legislative output, approved annual budget, Federal Constitution of 1988 and minutes of national health conferences) were selected and analyzed in order to identify the attention of these actors to specific topics on health policy. The frequency analyses, both on longitudinal and cross-sectional perspective, are based on a large set of data that reflect the government's attention during the first decades after the re-democratization in Brazil and allow for the observation and maintenance of changes in health policies. As a result, it was possible to identify permanence in the government attention on health policies throughout the analyzed period, showing a permanent and constant degree of attention to this sectoral policy. From the dynamics point of view, maintenance, discrete and incremental adjustments in health policy were identified most of the time, but also moments of great transformations were punctuated during the period.

Keywords: Public Policy; Policy Agenda; Health Policy; Policy Dynamics.
As políticas públicas de saúde são temas de maior relevância nas sociedades contemporâneas e tópicos recorrentes em debates sobre as relações políticas, econômicas e sociais. Há, ao redor do mundo, inúmeros modelos e desenhos institucionais para sua promoção. No caso do Brasil pós-redemocratização, as prerrogativas constitucionais presentes na Carta Magna de 1988 garantiram a construção de um sistema de saúde universal calcado no reconhecimento da saúde como direito de cidadania e de responsabilidade do Estado. Dada essa importância e destaque sobre o sistema de saúde universalista, potencializado pela diferença de modelo adotado pelos demais países latino-americanos da época, diversos são os estudos que buscam analisar as políticas de saúde no Brasil (Bertolozzi; Greco, 1996; Biasoto Júnior; Silva; Dain, 2006). Este estudo tem como objetivo investigar um aspecto específico da política de saúde no Brasil: a dinâmica da atenção governamental sobre esse tema no período pósredemocratização, entre 1986 e 2003.

A literatura internacional sobre a formação da agenda governamental, marco teórico base para a análise deste artigo, pode ser classificada em quatro momentos principais (Capella; Brasil, 2015). Os estudos de agenda-setting, datados do início dos anos 1970 e propostos por Cobb e Elder (1971, 1972), procuraram explicar o processo de priorização e escolhas de demandas da sociedade e dos atores governamentais pelos tomadores de decisão, apontando, inicialmente, para um processo seletivo baseado na limitada atuação e capacidade das agendas. A década seguinte, que envolve os anos 1980 e 1990 nos Estados Unidos, apresenta um momento de grande expansão e fortalecimento dos estudos de agenda com o surgimento de teorias gerais que deslocaram o foco de investigações pontuais para a construção de grandes modelos teóricos-metodológicos que propunham explicações gerais sobre o processo de formação e mudança da agenda governamental. O Modelo de Múltiplos Fluxos, de John Kingdon (2003), o Modelo de Equilíbrio Pontuado, de Baumgartner e Jones (1993) e o Modelo das Coalizões de Defesa, de Sabatier 
e Jenkins-Smith (1993), surgem, então, como as principais inovações nos estudos da formação da agenda governamental. O terceiro momento é marcado pela difusão desses modelos para fora do contexto estadunidense e pela proliferação de trabalhos aplicados em diversos estudos de caso, em diferentes contextos nacionais. Marca também momentos de adaptações, adequações e revisões dos preceitos originais dos três modelos mencionados. O quarto e mais recente movimento da literatura (2ooo-atualmente) tem focalizado o estudo das agendas em perspectiva comparada.

As investigações sobre formação de agenda têm se dedicado a identificar mudanças na atenção governamental - ou seja, movimentações na agenda - em torno de diferentes políticas públicas, durante longos períodos e em diferentes sistemas políticos. Esse esforço enfrenta uma série de desafios e tem produzido um rico debate na literatura internacional, definindo indicadores de atenção governamental válidos para os diversos contextos político-institucionais e desenvolvendo categorias válidas do ponto de vista comparativo, testes de resultados, entre outras questões de ordem teórico-metodológica (Baumgartner; Green-Pedersen; Jones, 20o6; Baumgartner; Jones; Mortensen, 2014).

Entre as inovações mais recentes sobre o processo de formação e de mudança da agenda governamental, especial atenção tem sido dada ao processamento de informação e, nesse aspecto, à amplitude de atenção que atores e instituições dispensam a determinados temas (Baumgartner; Jones, 2015; Jones; Baumgartner, 2005). Como veremos a seguir, essa literatura considera que a produção de políticas se desenvolve em um contexto de ambiguidade e incerteza, elementos responsáveis pela desproporcionalidade no processamento de informações de atores que formam a agenda. Isso significa que os atores envolvidos com a formulação interpretam sinais do ambiente, selecionando e filtrando informações disponíveis sobre problemas e soluções. Nesse contexto, a atenção desses mesmos atores é, também, desproporcional: concentra-se em alguns problemas ou soluções em detrimento de outros. Examinar a dinâmica da atenção governamental ajuda a explicar as pontuações na produção de políticas, ou seja, momentos em que essas políticas mudam de forma lenta e incremental e momentos em que elas mudam de forma rápida e abrupta.

A formação da agenda governamental entendida como conjunto de questões sobre o qual os policymakers (atores do governo e pessoas ligadas a ele) concentram sua atenção num determinado momento (Kingdon, 2003, p. 3) - é um dos aspectos centrais do processo de produção de políticas públicas. Considerando que a atenção é um recurso escasso (Jones; Baumgartner, 2005), e que tanto pessoas quanto organizações estabelecem prioridades de atuação, estudar agenda significa identificar como o governo distribui atenção entre as diversas questões existentes, decidindo o que é um problema a ser priorizado (Baumgartner; Jones, 2015). Entender de que forma alguns problemas são percebidos como mais importantes do que outros em um determinado momento, mobilizando a ação governamental, é precisamente o ponto central dos estudos de agenda. Dito de forma simples e objetiva, "agenda-setting é simplesmente o processo pelo qual uma organização passa a prestar atenção em algumas questões em vez de outras" (Jones; Baumgartner, 2005, p. 38). A desproporcionalidade - de informação e de atenção está na base da explicação sobre as pontuações nas políticas públicas (Baumgartner; Jones, 2015; Jones; Baumgartner, 2005). Ao selecionar informações e dirigir sua atenção a algumas questões específicas, os formuladores tendem a priorizar elementos mais ajustados às suas próprias crenças e preferências, buscando também adaptar a política à legislação e às normas existentes. Tem-se nesse caso uma mudança lenta e incremental. 0 mesmo processo explica também as mudanças rápidas, abruptas e muitas vezes imprevisíveis: questões negligenciadas podem subitamente se tornar proeminentes (em função de um evento externo, por exemplo), atores previamente excluídos do policymaking podem levar as questões a arenas institucionais mais favoráveis, ampliando o conflito e mobilizando novos atores, entre outras possiblidades que favorecem mudanças rápidas.

Esse é, em linhas gerais, o principal argumento da "tese geral sobre a pontuação" (Baumgartner; 
Jones, 2015; Jones; Baumgartner, 2005), ${ }^{1}$ uma abordagem teórica que destaca o papel do processamento de informações no sistema político para explicar a mudança na agenda e, de forma mais geral, nas políticas públicas. Essa abordagem amplia a primeira proposição do Modelo de Equilíbrio Pontuado, que oferecia explicações para as mudanças verificadas em casos específicos, caracterizados como monopólios de políticas no contexto do sistema político estadunidense (Baumgartner; Jones, 1993).

Dentre as diferentes abordagens contemporâneas para o estudo da agenda governamental, este artigo optou pela Teoria do Equilíbrio Pontuado, destacando a ideia de dinâmica de políticas públicas (policy dynamics). É empregada hoje em estudos que buscam identificar elementos da atenção da agenda governamental, uma vez que oferece explicações para mudanças em políticas públicas considerando diversos atores e arenas do sistema político, utilizando grande quantidade de dados durante longos períodos de tempo e, conforme evidenciado em estudos anteriores, é aplicada a diferentes contextos nacionais e sistemas políticos (Baumgartner; Jones; Wilkerson, 2011). Além disso, no que compete à inovação e contribuição para a literatura de agenda-setting e de análise de políticas públicas, são apresentados neste artigo os primeiros resultados de análises de políticas públicas brasileiras a partir da teoria geral da pontuação e do método do Policy Agendas Project no Brasil. Outros estudos mapeados (Capella; Soares; Brasil, 2014) se utilizam de termos ou conceitos isolados da teoria de Baumgartner e Jones (1993; Jones; Baumgartner, 2005), mas não a completude de sua proposição teórica e metodológica - como apresentado neste artigo - aproximando os estudos nacionais e sobre políticas nacionais do que há de mais recente e complexo sobre análise de dinâmica de políticas na literatura internacional.

Partindo do pressuposto de que a formulação da política de saúde no Brasil no período pósredemocratização desenvolveu-se em um contexto institucional de ambiguidade e incerteza, marcado pelo processamento desproporcional de informação e atenção - característico de mudanças macrossistêmicas como a alteração de regime político e de novas configurações de suas instituições -, buscamos responder às seguintes questões: há mudanças significativas na atenção governamental dos atores selecionados sobre as políticas de saúde? Qual o grau de atenção desses atores e instituições brasileiras sobre as políticas de saúde ao longo do tempo? Há momentos em que a saúde não entra na agenda? Quais temas vinculados às políticas de saúde apresentam maior e menor prioridade na atenção dos atores estudados? Há proximidade ou distanciamento sobre os níveis de atenção quando comparamos diversos loci, como o Poder Executivo, o Poder Legislativo e as Conferências Nacionais de Saúde? A partir dessas perguntas, o trabalho tem como objetivo central identificar e analisar a dinâmica da agenda governamental sobre as políticas de saúde, ou seja, mapear e analisar a atenção dos atores e instituições selecionados e que compõem a agenda governamental sobre elas, contribuindo para a compreensão de mudanças e continuidades na agenda dessa política pública durante o período de 1986 a 2003.

Para tanto, empregaremos as bases metodológicas desenvolvidas inicialmente por Baumgartner e Jones (1993) para a investigação da Teoria do Equilíbrio Pontuado e que posteriormente passaram a subsidiar as pesquisas do Comparative Agendas Project (CAP) (Baumgartner; Jones, 2002, 2015; John, 2006). Visando uma abordagem que combine estudos transversais e longitudinais, Baumgartner e Jones (1993) identificaram um conjunto de indicadores que refletisse a formação da agenda governamental e seus principais atores. Foram consideradas, na versão inicial do Equilíbrio Pontuado, as seguintes fontes de dados para a investigação da agenda governamental: audiências públicas para análise da atenção do Congresso; cobertura midiática para a compreensão do contexto em torno de uma questão que chega à agenda; e, em alguns casos, dados da opinião pública sobre diferentes questões. Esse

\footnotetext{
1 Os autores também denominam esse processo de "dinâmica disruptiva" (disruptive dynamics) na segunda edição de Agendas and instability in American politics, publicada em 2009.
} 
esforço inicial, que culminou no livro lançado em 1993, serviu como base para o desenvolvimento de um ambicioso projeto - o Policy Agendas Project. Para essa nova etapa da pesquisa foram ampliadas as fontes de dados para sete grandes conjuntos: (1) mídia, (2) legislativo; (3) executivo; (4) partidos; (5) judiciário; (6) orçamento; e (7) opinião pública e grupos de interesse. Os mais de 20 grupos nacionais que integram o Comparative Agendas Project basearam suas análises em alguns desses indicadores, com adaptações feitas de acordo com o sistema político e institucional de cada país e de acordo com a necessidade demandada por cada política setorial objeto de análise. Para a estruturação da pesquisa no Brasil, foram definidos inicialmente três conjuntos de dados, vinculados ao Poder Executivo, Legislativo e à mídia (Capella; Brasil; Sudano, 2015). ${ }^{2}$

Para este artigo, em especial, os indicadores de atenção a serem investigados para aferir e analisar a atenção da agenda governamental sobre as políticas de saúde no Brasil são: produção legislativa, envolvendo leis, leis complementares, medidas provisórias (MP), emendas constitucionais e decretos do Legislativo e do Executivo; a Constituição Federal; mensagens ao Congresso Nacional, orçamento anual aprovado; e relatórios das Conferências Nacionais de Saúde. Na próxima seção justificaremos as escolhas dos indicadores e apontaremos ausências de outros indicadores, como as portarias, resoluções e atuação ministerial.

O artigo está estruturado em quatro seções. Nesta primeira, introdutória, apontamos, além dos objetivos deste estudo, o referencial teórico dos estudos de agenda-setting e da dinâmica de políticas (policy dynamics), sobre as quais toda a análise será realizada. Na segunda seção são apresentadas as concepções metodológicas vinculadas aos estudos de agenda, suas ferramentas analíticas, bem como as justificativas das escolhas pelos indicadores selecionados por esta pesquisa. A terceira seção traz os resultados de análises longitudinais, orçamentária e de diversidade da atenção na agenda governamental sobre as políticas de saúde no
Brasil. Na quarta e última seção, apresentamos as conclusões deste estudo, apontando os principais resultados encontrados, diálogo com a literatura existente, bem como os limites dessa pesquisa e propostas para novas, a partir dos resultados encontrados.

\section{Metodologia e formas de análise}

Frank Baumgartner e Bryan Jones deram início, ainda em meados dos anos 1990, àquilo que viria a se tornar um dos mais complexos e importantes projetos de análise da dinâmica das políticas públicas de seu país - o U.S. Policy Agendas Project e, posteriormente, do mundo, com a criação do CAP. O projeto é conduzido por uma estrutura complexa de escolha, coleta, sistematização e tratamento de dados e pode ser resumido pelas análises de um grande conjunto de informações que refletem a atenção governamental ao longo de algumas décadas, permitindo observar o status de uma ou mais políticas ao longo do tempo e em perspectiva comparada entre diferentes países (Baumgartner; Jones; Wilkerson, 2002).

Este artigo é fruto dos primeiros resultados da aplicação desse desenho de pesquisa para o estudo da agenda governamental no Brasil, com foco na dinâmica das políticas de saúde do país nas duas primeiras décadas pós-redemocratização, entre 1986 e 2003. Um dos primeiros desafios na adaptação deste projeto internacional para a construção de estudos sobre a dinâmica das políticas brasileiras está na seleção de indicadores da agenda governamental adequados para sinalizar a mudança de atenção sobre as políticas públicas. Conforme visto na literatura internacional, Baumgartner e Jones apontam diversos indicadores possíveis para mapear e analisar a agenda governamental. Legislação, discursos presidenciais, falas parlamentares, mídia e orçamento, por exemplo, estão entre os principais dados utilizados por pesquisadores do CAP (Baumgartner; GreenPedersen; Jones, 2oo6; Baumgartner; Jones; Wilkerson, 2011).

\footnotetext{
2 Para mais informações sobre o processo e construção do Brazilian Policy Agendas Project, sobretudo os critérios de adaptação e de escolha de documentos e indicadores de atenção da agenda governamental brasileira, ver Capella, Brasil e Sudano (2015).
} 
Partindo, então, dos dados inicialmente selecionados pelo Laboratório da Agenda Governamental Brasileira (Capella; Brasil; Sudano, 2015), as reflexões metodológicas acerca da atenção sobre as políticas de saúde no Brasil nos levaram à escolha de dados baseados em três diferentes loci de atenção: o Poder Executivo, o Poder Legislativo e as instituições de participação social em políticas e saúde. Com base nessa definição, cinco fontes de dados foram selecionadas: orçamento anual aprovado (1995 a 2003); a Constituição Federal (1988); mensagens ao Congresso Nacional (1986 a 2003); produção legislativa, envolvendo leis, leis complementares, medidas provisórias, emendas constitucionais e decretos do Legislativo e do Executivo (1986 a 2003); e relatórios das conferências nacionais de saúde (1986, 1992, 1996, 2000, 2004). A escolha dessas fontes de dados foi pautada na compreensão dos principais autores dos estudos de formação de agenda, que consideram predominante o papel desempenhado pelo chefe do executivo nacional e os atores que integram o Poder Legislativo, entendidos como policymakers centrais ao processo de agenda-setting (Kingdon, 2003; Baumgartner; Jones, 1993). Também condiz com aquilo que vem sendo produzido pelos grupos de pesquisas internacionais vinculados ao CAP, que têm selecionado como indicadores mais frequentes para a investigação da agenda os discursos ou mensagens oficiais do chefe do executivo e a produção legislativa dos atores envolvidos no processo de agendamento para mapear e analisar a agenda governamental de seus países.

Baumgartner e Jones (1993) tomam como indicador de atenção presidencial os discursos sobre "o Estado da Nação" (Presidential State of the Union Speeches), discursos anuais proferidos pelo presidente ao Congresso estadunidense, além das produções normativas que cabem ao chefe do Executivo. Assim, embora os instrumentos sejam específicos de cada contexto, considerando o sistema político e as nomenclaturas de cada nação, na maior parte dos casos a análise concentra-se em discursos anuais originados no Poder Executivo (Baumgartner; Jones; Wilkerson, 2011). Buscando um indicador nacional dessa esfera, as mensagens ao Congresso Nacional foram selecionadas obedecendo a critérios mínimos, como ser um documento capaz de traduzir as prioridades do presidente para um determinado período e ter periodicidade de publicação, sendo editado de forma sistemática e frequente, para permitir comparações ao longo do tempo. Tais dados são disponibilizados no site da presidência da República.

Outro indicador de maior validade na análise da atenção governamental é a distribuição orçamentária anual. Conforme veremos na análise de curtoses, a forma como o orçamento é distribuído entre as pastas destinatárias de receitas produz indicativos de manutenção e de mudança na composição da agenda governamental (Tabela 1, Gráfico 1).

No que tange aos dados da Constituição Federal de 1988 e da produção legislativa, quer do Poder Executivo, quer do Legislativo, eles são, em essência, o resultado do processo político de arenas institucionais de extrema relevância no sistema político brasileiro, no qual os players atuam e advogam por suas ideias, valores e interesses em um processo competitivo e limitado. Não se pode legislar sobre tudo, a todo tempo. O processo de seleção dos temas objeto de atuação parlamentar, no caso do Legislativo, é base para todos os estudos de agenda-setting em análises longitudinais e transversais. Destaque a esse indicador deve ser dado às prerrogativas legislativas do Poder Executivo, sobretudo os instrumentos de decretos e medidas provisórias. Os dados são extraídos do sistema LexML, Rede de Informação Legislativa e Jurídica do Governo Federal. A partir da totalidade dos dados apresentados pelo LexML, foram selecionados apenas os dados de seis espécies normativas: "leis", "leis complementares", "medidas provisórias", "emendas constitucionais", "decretos do executivo" e "decretos do legislativo" de todo o período (1986-2003).

Uma nota metodológica se faz necessária sobre a definição de agenda governamental e o processo de seleção de indicadores que possam refletir as prioridades dessa agenda sobre as políticas de saúde no Brasil. Segundo Kingdon (2003) e, sobretudo, a teoria e consequentes aplicações de Baumgartner e Jones (1993; Jones; Baumgartner, 2005), diversos são os atores, de dentro e de fora do Estado, que têm capacidade e poder de influenciar a formação 
e ocasionar mudanças na agenda governamental. A mídia, os partidos políticos, atores e instituições do Poder Judiciário e os grupos de interesse são exemplo, também reconhecidos como policymakers, sobretudo em algumas políticas setoriais, que atuam, de forma mais ou menos direta, no processo de agenda-setting.

A agenda governamental não é uma unidade finita e, por isso, mapeá-la significa definir um conjunto de atores e instituições significativos para a análise pretendida. Desta forma, é preciso ressaltar que, para fins de compatibilidade com projetos correlatos no âmbito internacional, não foram considerados, neste trabalho, portarias, resoluções, instruções ou resoluções normativas. 0 estudo não contempla ações ministeriais, ainda que o Ministério da Saúde e a própria figura do ministro sejam importantes na definição de agendas setoriais. Neste estudo, a análise da agenda governamental está restrita aos dados obtidos dos atores e das instituições mencionados.

Os dados foram sistematizados e tratados pelo método de análise de conteúdo e codificação de dados. A codificação é uma ferramenta metodológica típica da análise de conteúdo capaz de transformar informações das mais distintas naturezas em variáveis pré-estabelecidas, ou códigos, comparáveis entre si. As variáveis utilizadas nesse processo estão organizadas em duas estruturas: a primeira contendo 22 macrocategorias, definidas pelo tipo de política pública setorial (exemplo: saúde, educação, macroeconomia, transporte, energia etc.), e, a segunda, por mais de 250 subcategorias, contendo especificações detalhadas dentro de cada um dos 22 macrocódigos (por exemplo: dentro da macrocategoria de energia, as subdivisões em energia elétrica, energia eólica, termoelétrica, petróleo e gás natural etc.).

O processo de codificação e controle metodológico respeita os preceitos do sistema double-blind, no qual, inicialmente, dois pesquisadores qualificados atribuem códigos para os dados informados. As decisões são comparadas e, com compatibilidade maior ou igual a 9o\%, os dados divergentes são separados e julgados por um terceiro pesquisador que define o código apropriado para a informação em questão. Após a codificação da totalidade do corpus documental, foram selecionados apenas os dados enquadrados nas políticas de saúde e seus respectivos subcódigos. Ou seja, de toda a produção legislativa de 1986 a 2003, ou de todos os fragmentos textuais extraídos das mensagens ao Congresso Nacional, foram selecionados para análise apenas aqueles dados que refletiam a atenção sobre políticas públicas codificados sob o código 3 - saúde. 0 banco de dados utilizado por essa pesquisa, portanto, é resultado de um processo de codificação integral do corpus documental duplamente checado, seguido da seleção de dados que pertencem, exclusivamente, ao código de políticas de saúde, formando, assim, um universo de mais de 10 mil informações.

Construir o banco de dados usando as informações brutas pode, no entanto, gerar desvios e enviesar as análises posteriores. É necessário que os dados passem por um tratamento estatístico e, no caso, um tratamento percentual sobre sua frequência, de forma que o dado reflita a fração de atenção sobre o total do documento analisado. A partir desse tratamento percentual, foram feitas diversas análises, como: análise de distribuição orçamentária com modelo de curtose e l-curtose; a análise de entropia e de diversidade da Constituição Federal de 1988; análise longitudinal das políticas de saúde entre seus códigos e subcódigos; e análises de correlação entre os distintos atores e instituições mapeados.

\section{Análise}

Dentre os resultados obtidos, é importante iniciar com a análise orçamentária do período em questão, realizada por meio dos modelos de curtose e l-curtose. É ferramenta de grande importância para aferir a existência de cenário permeado por ambiguidades e fricções sobre imagens de políticas entre os atores e instituições produtoras de políticas. Retomando a importância do conceito de fricção institucional e cognitiva, Jones e Baumgartner (2005) afirmam que é nesses momentos que imagens sobre políticas têm maiores chances de serem redefinidas, novos atores entram em cena e, consequentemente, políticas podem sofrer processos de maior mudança. 
Gráfico I - Análise de curtose e I-curtose sobre o orçamento autorizado, 1995-2003

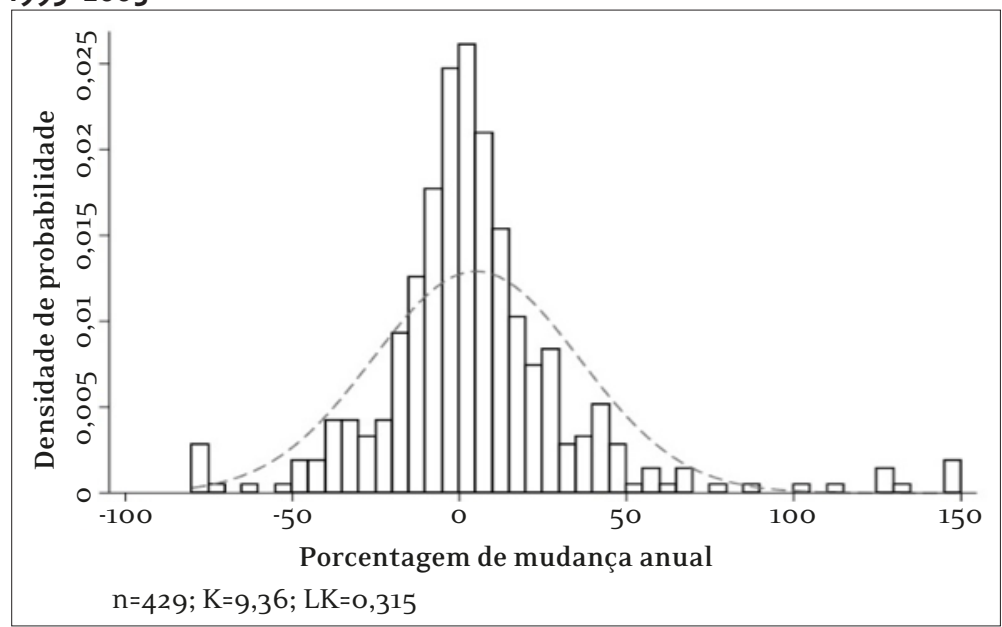

\begin{tabular}{ccc} 
& Orçamento $1995^{-2003}$ & Saúde $1995-2003$ \\
L-curtose & 0,315 & 0,100 \\
Curtose & 9,36 & 2,29 \\
$\mathrm{n}$ & 429 & 8 \\
\hline
\end{tabular}

n: tamanho da amostra; K: curtose; LK: I-curtose. Valores extremamente altos/baixos agrupados em +150 e -80

No Gráfico 1, "n=429" relaciona-se à quantidade de pastas ministeriais e instituições que se enquadram como fontes recebedoras do orçamento autorizado ao longo dos oito anos analisados. Com um "n" grande, apesar do pouco tempo analisado, é possível perceber as características gráficas de uma distribuição leptocúrtica, com curtose=9,36 e l-curtose $=0,315$. Este tipo de distribuição é um "indicador primário da desproporcionalidade no processo de escolha” (Jones; Baumgartner, 2005, p. 336) e indica fricção na atualização do processo orçamentário, levando a uma variação na tomada de decisão. Esse indicador aponta a existência de momentos de mudanças significativas na atenção governamental e que, unida às análises seguintes, pode demonstrar variações no grau de atenção de atores e instituições brasileiras sobre as políticas de saúde ao longo do tempo. Estabilidade na designação orçamentária, por outro lado, refletiria baixa fricção institucional e consolidação do processo decisório com manutenção de prioridades e de atuação governamental.

Outro indicador geral de grande importância para a análise da atenção e da dinâmica das políticas públicas está relacionado à Constituição Federal de 1988 (CF/88). Os resultados desta análise mostram uma composição temática da CF/88 extremamente interessante, conforme pode ser acompanhado na Tabela 1. Diversos estudos nacionais se dedicaram à análise da Constituição Federal, apontando especificidades relativas à produção de políticas públicas. Muito mais do que um documento de organização dos poderes e de normas de funcionamento de um sistema complexo, a Constituição garantiu uma série de direitos específicos, ou, pelo menos, abriu caminho normativo para construções de políticas futuras (Couto, 2005).

Tabela I - Percentual de atenção entre os tópicos e subtópicos na Constituição Federal de 1988

$\begin{array}{lclcc}\text { Tópico } & \text { Atenção \% } & \text { Subtópico } & \text { Atenção \% } \\ \text { 1-Macroeconomia } & 12,30 & 300-\text { Geral } & 27,9 & 19,3 \\ \text { 2-Direitos civis e minorias } & 5,3 & 301-\text { Sistemas nacionais de saúde } & 7,7 \\ \text { 3-Saúde } & 1,4 & 302-\text { Seguros, sistemas alternativos } & \text { continua... }\end{array}$


Tabela I - Continuação

\begin{tabular}{|c|c|c|c|}
\hline Tópico & Atenção \% & Subtópico & Atenção \% \\
\hline 4- Agricultura e pecuária & 0,9 & $304-$ Cuidados primários & 0 \\
\hline 5-Trabalho e emprego & 5 & 321 - Regulação farmacêutica & 3,8 \\
\hline 6-Educação & 4,4 & $322-$ Hospitais & 0 \\
\hline 7 -Ambiente & 1 & $323-$ Acordos & 0 \\
\hline 8 - Energia & 1,4 & 324 - Deodontia e fraudes & 0 \\
\hline 10-Transporte & $\mathrm{I}, \mathrm{I}$ & 325 - Carreiras e formação & 3,8 \\
\hline 12 - Justiça e crimes & 21,8 & 326-Regulação farmácias & 7,9 \\
\hline 13 - Políticas sociais & 2,5 & 331 - Prevenção e promoção & 11,5 \\
\hline 14 - Habitação & 2,8 & 332 - Saúde infantil e pré-natal & 0 \\
\hline 15 - Finanças e comércio & ।,8 & 333 - Saúde mental & 0 \\
\hline 16 - Defesa & 3,3 & 334 - Tratamentos continuados & 0 \\
\hline 17 - Tecnologia e comunicação & 1,6 & 335 - Medicamentos e custos & 0 \\
\hline 18 - Comercio exterior & 0,5 & 336 - Programas específicos & 0 \\
\hline 19-Política externa & 1,2 & $342-$ Tabagismo & 0 \\
\hline 20-Governo e adm. pública & 30,5 & 343 - Toxicodependência & 3,8 \\
\hline $21-$ Recursos naturais & 0,6 & 344 - Outras dependências & 3,8 \\
\hline $23-$ Cultura & 0,2 & $398-$ Pesquisa e desenvolvimento & 11,5 \\
\hline 29-Lazer & 0,2 & $399-$ Outros & 0 \\
\hline Total & 100 & Total & 100 \\
\hline Representação de 50\% & 2 & Representação de 50\% & 3 \\
\hline Capacidade & 1.819 & Capacidade & 26 \\
\hline Diversidade & 2,24 & Diversidade & 2,06 \\
\hline
\end{tabular}

As porcentagens somam $100 \%$ na coluna, indicando a parcela relativa de atenção em todos os tópicos. As três últimas linhas mostram, respectivamente, o número de tópicos que compõem metade do total, a capacidade e a diversidade da Constituição Federal de 1988. Além disso, considerando que nesta análise temos 21 tópicos, a diversidade máxima possivel é 3,1 .

O resultado aponta que $1,43 \%$ das normas da Constituição Federal de 1988 versam sobre a política de saúde. Ao todo, são 26 normas sobre o tema, constantes em artigos, parágrafos e incisos mapeadas na Constituição. 0 indicador de maior atenção está vinculado às questões gerais sobre a saúde (subcódigo 300), como o direito à saúde e às garantias fundamentais de atuação do Estado e a forma de acesso às providências e recursos. Essa alta atenção mostra, nesse momento, a preocupação e a priorização dos policymakers - neste caso os constituintes e atores envolvidos nos processos decisórios e atuantes em sessões temáticas da Assembleia Nacional Constituinte - com a construção das bases estruturantes do sistema de saúde brasileiro: garantir o direito a um sistema público, universal e gratuito. Também aparecem questões mais específicas sobre desenho, organização e formação do sistema de saúde, questões relacionadas à arrecadação, centralização e descentralização de estruturas e responsabilidades, temas presentes no código 301. Entretanto, ainda que com menor atenção, outros oito temas aparecem na Carta Magna, mostrando alto grau de capacidade e diversidade na normatização da Constituição Federal.

Buscando respostas para questões relacionadas à permanência e ao grau de atenção de atores dos poderes Executivo e Legislativo brasileiro sobre as políticas de saúde, as análises longitudinais apresentadas no Gráfico 2 indicam dois tipos de resultados. 0 primeiro deles mostra a existência de atenção sobre saúde em todo o período analisado, ainda que com variações no grau e na prioridade que o tema alcança nos documentos. 
Gráfico 2 - Percentual de atenção sobre a área de saúde considerando o total de legislações e mensagens ao Congresso

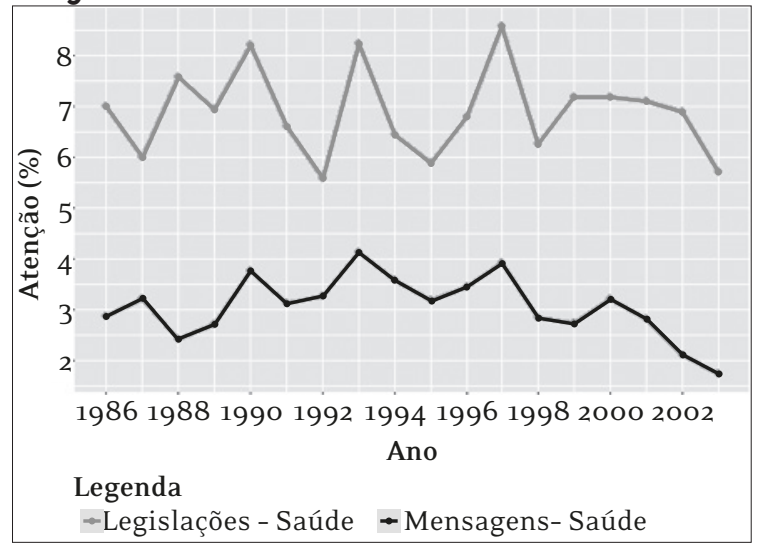

De forma mais detalhada, a dispersão gráfica das políticas de saúde ao longo do tempo evidencia alguns comportamentos importantes para esta análise. 0 primeiro deles responde diretamente a uma das questões levantadas sobre a permanência ou não das políticas de saúde na atenção governamental no período analisado. Com períodos de maior ou menor atenção, é possível aferir, no entanto, que as políticas de saúde sempre estiveram na agenda governamental ao longo de todo o período. No que diz respeito ao grau de atenção de cada tipo de dado selecionado, inicialmente sobre as legislações aprovadas, a análise mostra uma distribuição sem muitos desvios do comportamento médio, ou seja, um equilíbrio de atenção dado pelos legisladores ao setor da saúde. Apesar de mostrar três pequenos picos de atenção, cujos valores chegam a quase $4 \%$ de toda legislação produzida, em 1990, 1993 e 1997, a normatização sobre saúde se mostra bastante estável. Por outro lado, a atenção extraída das mensagens ao Congresso apresenta um comportamento bem menos estável e com pontuações muito bem definidas. Com picos de atenção que superam os $8 \%$ de cobertura dos documentos textuais enviados ao Congresso Nacional, os mesmos anos de 1990, 1993 e 1997 concentram a atenção do presidente da República, evidenciando momentos de forte atenção sobre políticas de saúde.

É importante retomar, desde já, características de instituições políticas brasileiras, sobretudo o poder e a autonomia legislativa do Poder Executivo, destacando a figura do próprio presidente no processo de produção legal via decretos e medidas provisórias de forma rápida e com baixa necessidade de negociação com outros atores, mesmo que de forma temporária. Essa autonomia é responsável pela maior capacidade e diversidade de atuação do Poder Executivo sobre a produção de políticas públicas (Abranches, 1988; Rodrigues; Zauli, 2002). Além disso, as mensagens do presidente ao Congresso Nacional evidenciam também a sua ação direta na formação de coalizões e maiorias para maior capacidade de governabilidade e de possíveis conversões de medidas provisórias em leis.

As técnicas de mineração de dados nos permitem analisar mais profundamente a concentração de atenção sobre políticas de saúde. Mais do que apontar quanto se fala sobre a política setorial, nos permitem entender, também, sobre o que que se fala dentro das políticas de saúde. As análises seguintes, presentes nos Gráficos 3 e 4, quebram os dados totais de atenção em dados percentuais de assuntos específicos (subcódigos), evidenciando sua entrada, saída ou permanência na agenda desses atores e os temas vinculados às políticas de saúde que apresentam maior e menor prioridade.

\section{Gráfico 3 - Percentual de atenção sobre subtópicos da saúde por ano nas mensagens ao Congresso Nacional}

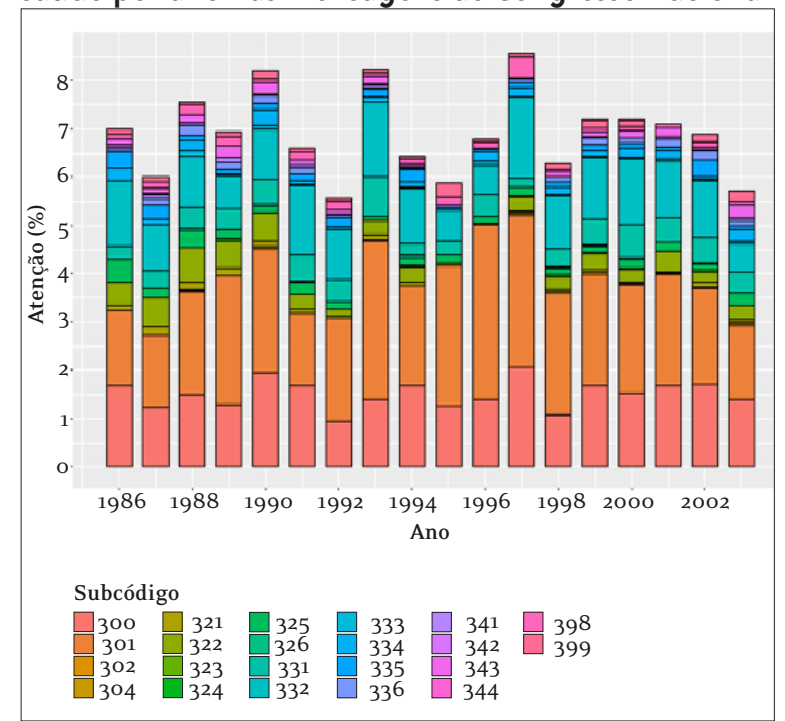

A composição dos indicadores de atenção de saúde em mensagens ao Congresso mostra 
consistência e permanência de temas ao longo do tempo, com pouca variação. A distribuição mostra que temas como a saúde geral (300), que trata sobre a saúde como direito, com garantias e acesso, se mantêm constantes na atenção da presidência. O mesmo ocorre, com algumas variações, mas sempre como a mais frequente, no subcódigo 301, que trata do sistema de saúde. Aqui não podemos identificar a variável exclusivamente do Sistema Único de Saúde (SUS), no caso brasileiro, mas sim como todo o debate sobre os modelos e sistemas de saúde possíveis, que são mapeados nesse indicador. O pico de atenção encontrado em 1990 sobre o setor da saúde deve-se, sobretudo, ao crescimento da atenção sobre esses dois temas, em específico na proposta de debate do Executivo sobre questões que seriam alvo da Lei no 8.142/1990. Há nítida antecipação das negociações e debate dentro do Executivo e na sua relação com o Legislativo, no que tange à participação popular e à transferência de recursos, tópicos presentes na Lei n 8.080/1990 (Lei Orgânica da Saúde).

Outro indicador relevante, presente em toda a série histórica, é o 332, que trata da saúde infantil e pré-natal. Em 1993, o crescimento deste tema relacionava-se aos altos índices de mortalidade infantil vivenciados pelo país, a promoção pelo Executivo do Programa Saúde da Família e questões voltadas às consequências da pobreza e da miséria. Outro parâmetro de entrada pode ser notado no indicador 302, que versa sobre seguros, planos de saúde e sistemas alternativos de acesso à saúde. 0 tema, que não aparecia na série histórica, aparece com destaque em 1997 e 1998 na agenda da presidência da República - anos em que há maior número de medidas provisórias editadas pelo presidente -, que antecipa questões que entrarão na agenda do Legislativo, como a Lei no ${ }^{0} .656 / 1998$, sobre regulamentação dos Planos e Seguros Privados de Assistência à Saúde.

\section{Gráfico 4 - Percentual de atenção sobre subtópicos da saúde por ano na produção legislativa total}

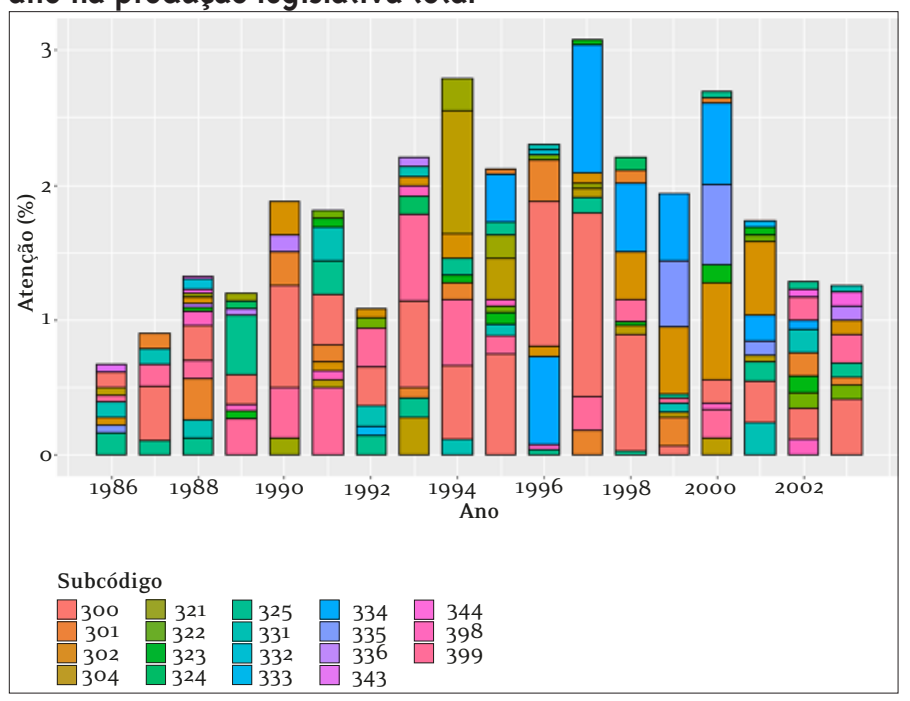

A distribuição da atenção sobre as políticas de saúde nas legislações aprovadas mostra a ascensão de novas políticas e a entrada de novos temas na agenda dos legisladores. Verifica-se a constante produção de normas e legislações sobre o funcionamento geral das políticas de saúde. O período de 1986 a 1994, sobretudo de 1990 a 1994, configura uma atuação quase exclusiva do
Poder Executivo na proposição de normas, com alto grau de concentração temática sobre acesso, financiamento e funcionamento dos serviços de saúde. Esse tópico, com maior ou menor atenção, aparece de forma constante ao longo dos anos, sobretudo por atuação legislativa do Poder Executivo sobre a organização, administração e regulação do setor. 
Dois momentos devem ser destacados nessa primeira fase: o ano de 1990, com a aprovação da Lei $n^{0} 8.080$, e o ano de 1994, que apresenta pico de atenção à saúde, com prioridade sobre políticas de cuidados primários. O segundo período, que vai de 1995 até 200o, apresenta um cenário de maior diversidade e capacidade média na produção de legislações sobre a saúde. A maior estabilidade econômica e política dos governos de Fernando Henrique Cardoso e a consolidação do Plano Real reduziram os custos de oportunidade, transação e decisão, abrindo oportunidades para mudanças em políticas. O Poder Legislativo aumenta significativamente sua atuação - quando comparado ao período anterior -, e há evidente aumento na pluralidade de temas que seus atores inserem na agenda governamental.

Destaque deve ser dado ao ano de 1997, com crescimento do número de normatizações sobre políticas de cuidados continuados, reabilitação e doenças terminais, unido às legislações gerais e atualizações sobre o funcionamento do SUS, que colocam aquele ano como o de maior produção normativa total da série analisada. É, também, o ano de maior atuação direta do Poder Executivo na proposição de medidas provisórias, exemplificadas pelas 45 MP editadas entre 1997 e 1998, versando sobre regulação de planos privados de saúde, que se tornaria lei em 1998 (Lei n 9.656). Ainda nesse período, o ano 2000 apresenta um segundo pico de atenção que se deve à concentração de legislações nas áreas de medicamentos, planos de saúde e cuidados primários, com destaque para o acesso de medicamentos para a aids e cuidados primários envolvendo promoção de saúde e prevenção contra doenças sexualmente transmissíveis.

Por fim, o terceiro período, que envolve os anos de 2000 a 2003, fim do segundo governo Fernando Henrique Cardoso e início do governo Lula, é caracterizado pela redução da atenção dos poderes sobre a política de saúde, com manutenção temática dentro do setor e baixa atuação de ambos os poderes. A produção normativa se traduz em atualizações e mudanças incrementais no SUS e no fomento de dias comemorativos de prevenção de doenças e promoção da saúde, atendendo a pressões de demandas sociais e corporativas "num nítido exemplo de conexões eleitorais" (Baptista, 2010, p. 107).

\section{Gráfico 5 - Análise comparada da atenção sobre subtópicos da saúde, por ano, na produção legislativa total e nas mensagens ao Congresso}

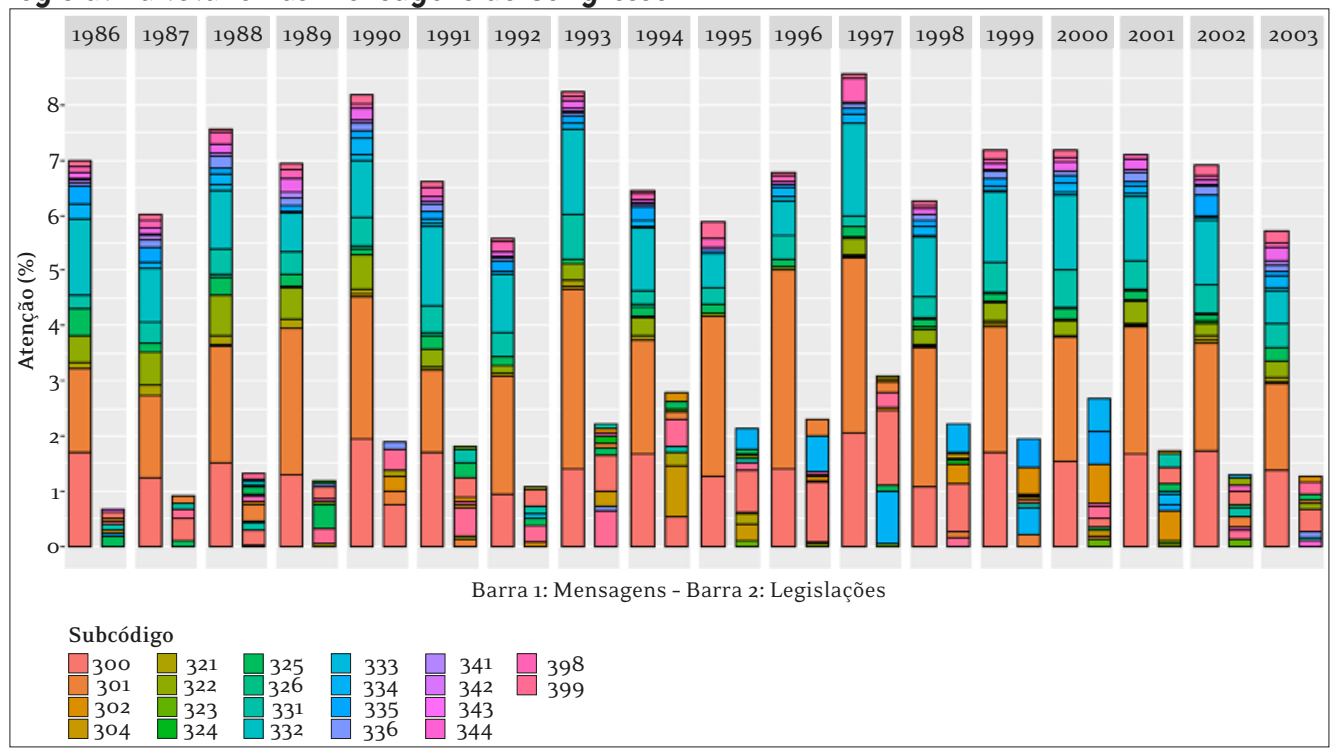


Tabela 2 - Correlação linear de Pearson entre os subcódigos das legislações e mensagens ao Congresso na área da saúde, por ano

\begin{tabular}{lllllllllllllllllllllll} 
& \multicolumn{1}{c}{ Correlação Linear de Pearson entre os subcódigos das legislações e mensagens ao congresso na área da saúde por ano } \\
\cline { 2 - 3 } & 1986 & 1987 & 1988 & 1989 & 1990 & 1991 & 1992 & 1993 & 1994 & 1995 & 1996 & 1997 & 1998 & 1999 & 2000 & 2001 & 2002 & 2003 \\
Correlação & 0,221 & 0,59 & 0,823 & 0,056 & 0,587 & 0,361 & 0,114 & 0,144 & 0,161 & 0,242 & 0,469 & 0,404 & 0,247 & 0,06 & $-0,11$ & 0,089 & 0,569 & 0,534 \\
\hline
\end{tabular}

Os achados na análise dialogam com a literatura especializada sobre política de saúde, sobretudo aquela que se dedica à análise da produção legislativa em saúde, quer do Poder Executivo, quer do Legislativo. A análise realizada evidencia momentos distintos que caracterizam as primeiras décadas do período pós-redemocratização do Brasil (Baptista, 2010; Machado; Baptista; Nogueira, 2011; Rodrigues; Zauli, 2002). De acordo com Baptista (2010, p. 105),

o primeiro, de definição da base institucional do SUS (1990-1994); o segundo, de expansão de políticas técnicas e específicas de saúde, seguidas de uma política de regulação do mercado em saúde (1995-2002); o terceiro, de retorno das políticas específicas diretamente atreladas a um projeto do Governo Federal (2003-2006).

Este artigo capta os dois primeiros momentos e a transição para o terceiro.

Quando analisamos o grau de compatibilidade temática entre as duas fontes de dados analisadas, mensagens ao Congresso Nacional e o total das legislações aprovadas, é possível entender as temáticas prioritárias motivadoras de picos de atenção dentro da política de saúde. Em primeiro lugar, é possível aferir a existência de um período inicial com alto grau de relação temática entre a fala do Executivo e a produção legal. Tal aproximação é explicada por dois fatores: o primeiro relaciona-se à baixa diversidade temática e alta concentração em temas relacionados à consolidação do sistema de saúde. Questões administrativas, organizacionais e de consolidação setorial dominam o debate ao mesmo tempo que, em segundo lugar, é o próprio Poder Executivo o responsável pela maior parte da produção normativa do período, chegando a picos de $90 \%$ de toda produção normativa da época, via medidas provisórias e decretos, em alta correspondência temática com o conteúdo de suas mensagens ao Congresso Nacional.

No segundo momento, entre 1995 e 2000 , a diversidade da agenda se torna maior, com mais atuação do Poder Legislativo e menor correlação entre a produção legislativa total e o conteúdo das mensagens ao Congresso Nacional. A estabilidade econômica encontrada pós-Plano Real e a maior atuação do Poder Legislativo sobre temas advindos de pressão social e coorporativa apontam menor concentração e maior diversidade temática na agenda em saúde do período. No entanto, em meio a um período de maior incrementalismo e ajustes na atuação do Executivo sobre as políticas de saúde, é possível perceber dois momentos de pontuação do equilíbrio e de crescimento abrupto de temáticas que refletem na agenda do Legislativo. Os anos de 1997, 1998 e 2000 focam suas normatizações específicas em planos de saúde, sistemas alternativos, acordos de cooperação e regulação farmacêutica e de medicamentos, agendas que nascem no Poder Executivo, com forte atuação da presidência em medidas provisórias e com alto grau de atenção nas prioridades listadas nas mensagens ao Congresso Nacional dos anos citados. No primeiro caso, entre 1997 e 1998, os esforços na saúde se voltavam para a regulamentação de planos de saúde privados, vinculados a uma nova lógica de atuação regulatória do Estado e promoção via mercado. No segundo caso de pico de atenção, somam-se a essas mudanças liberais a ascensão de questões vinculadas aos medicamentos, controle e prevenção da aids.

Buscando indicadores de atenção alternativos aos já analisados, que possam apresentar relações menos institucionalizadas, mapeamos os relatórios das conferências nacionais de saúde de 1986 , 1992, 1996, 2000 e 2004. Ao analisar o conteúdo desses documentos, buscamos, em primeiro lugar, verificar as demandas mais frequentes nesse espaço com características participativas próprias, 
menos restrito e mais plural, para que, numa segunda avaliação, pudéssemos fazer uma análise comparada entre essas demandas e as prioridades governamentais.

\section{Gráfico 6 - Análise da atenção sobre a saúde nas conferências nacionais de saúde}

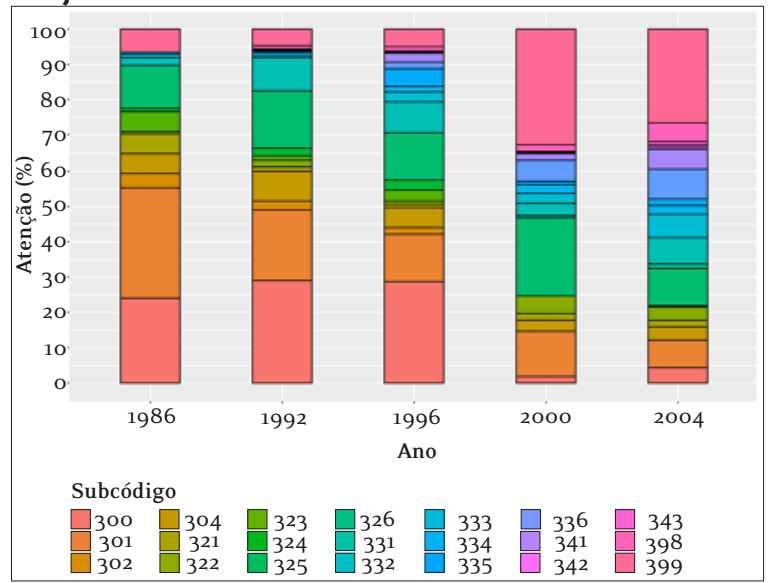

A icônica Conferência Nacional de 1986 apresenta forte concentração temática nos tópicos 300 e 301, geral e sistemas de saúde, uma vez que preza a criação da Lei Orgânica da Saúde e a criação do SUS. O período, marcado pelo debate sobre a forma como o sistema de saúde seria estruturado, também aparece em outros indicadores de atenção. Menos concentrada, a atenção da conferência de 1992 apresenta forte crescimento sobre o exercício da profissão, organização de carreiras e formação profissional, além das prioridades mantidas na saúde, como direito, e sobre o sistema de saúde. A conferência seguinte, de 1996, apresenta temas ainda não tratados nas conferências anteriores. Cresce o número de diversidade com a inclusão de novas pautas com programas específicos, como saúde da criança, questões relacionadas às mais diversas dependências e a atenção sobre cuidados primários e preventivos na saúde.

Uma inversão nas prioridades desse locus de atenção marca as conferências nacionais de saúde realizadas em 200o. 0 indicador de maior atenção passa a se referir à participação popular no processo de tomada de decisão e de formulação de políticas de saúde. Outro indicador que cresce nesse momento está voltado às questões de despesas com medicamentos, além da continuidade da diversidade sobre políticas específicas. 0 padrão da Conferência de 2004 segue o encontrado em 200o, com destaque para a atenção sobre políticas de prevenção e promoção da saúde. O Gráfico 6 mostra essa inversão a partir de 2000.

A base fundamental da atenção nas conferências nacionais de saúde de 1986, 1992 e 1996 está concentrada nos indicadores gerais de saúde, com destaque para os códigos 300 e 301. Novamente, como constatado nos demais indicadores, a atenção sobre estruturação, acesso e funcionamento do SUS predomina na atenção desse indicador. A partir de 2000, a atenção sobre esses códigos é extremamente reduzida, ao passo que a atenção sobre o indicador 399 sobe de forma exponencial. 0 indicador 399 , nas conferências nacionais, é composto, sobretudo, por questões relacionadas à participação popular nos processos de formulação de políticas na saúde. Nesse espaço há, portanto, um deslocamento de grande impacto entre o foco da atenção de seus participantes entre a Conferência de 1996 e a de 200o. Outra constatação relevante está na manutenção de alta atenção sobre carreiras profissionais e formação. A natureza desse espaço o caracteriza como locus de forte atuação e pressão das categorias profissionais.

Tabela 3 - Correlação linear de Pearson entre os subcódigos de saúde nas legislações, mensagens ao Congresso e conferências na área da saúde, por ano

\begin{tabular}{|c|c|c|c|c|c|c|c|c|c|c|c|c|c|c|c|c|c|c|}
\hline \multirow[b]{2}{*}{ Ano } & \multicolumn{18}{|c|}{ Correlação Linear de Pearson entre os subcódigos das legislações e mens. ao congresso e conf. na área da saúde por ano } \\
\hline & 1986 & 1987 & 1988 & 1989 & 1990 & 1991 & 1992 & 1993 & 1994 & 1995 & 1996 & 1997 & 1998 & 1999 & 2000 & 2001 & 2002 & 2003 \\
\hline Legisl/ - Mens. & 0,221 & 0,59 & 0,823 & 0,056 & 0,587 & 0,361 & 0,114 & 0,144 & 0,161 & 0,242 & 0,469 & 0,404 & 0,247 & 0,06 & $-0,11$ & 0,089 & 0,569 & 0,534 \\
\hline Legisl/ - Conf. & 0,342 & 0,72 & 0,887 & 0,374 & 0,683 & 0,526 & 0,61 & 0,623 & 0,516 & 0,67 & 0,787 & 0,745 & 0,711 & 0,075 & 0,034 & $-0,08$ & 0,416 & 0,347 \\
\hline Mens. - Conf. & 0,741 & 0,756 & 0,807 & 0,851 & 0,839 & 0,717 & 0,635 & 0,627 & 0,731 & 0,701 & 0,59 & 0,641 & 0,566 & 0,688 & 0,16 & 0,125 & 0,154 & 0,217 \\
\hline
\end{tabular}


Nota-se que o padrão de correlação de prioridades entre as conferências nacionais e os demais indicadores é maior no início do período de redemocratização nacional. Tanto com relação às mensagens ao Congresso quanto às legislações aprovadas, o período que vai de 1988 a 1998 mostra índices moderados e altos de correlação de prioridades entre esses indicadores. No entanto, há uma queda significativa nessa relação, sobretudo entre a produção legislativa e as conferências nacionais, mas também em relação às mensagens ao Congresso, que se estende de 1999 até 2003.

\section{Considerações finais}

Este artigo teve como principal objetivo analisar a atenção governamental de atores dos poderes Executivo, Legislativo e de espaços de participação social à luz da teoria do equilíbrio, pontuado sob a perspectiva do conceito de dinâmica de políticas. Após seleção, tratamento e análise de dados, foi possível identificar tanto momentos de estabilidade na atenção desses atores quanto momentos pontuados pelo crescimento abrupto na atenção sobre temas vinculados à política de saúde, mas, sobretudo, a permanência da atenção sobre a saúde em todo o período analisado. Além de demonstrar o grau de atenção sobre as políticas de saúde em perspectiva longitudinal e comparada a outras políticas setoriais, este estudo também possibilitou compreender melhor os assuntos internos da política de saúde como conjunto de outras variáveis mais específicas.

Dialogando com a literatura especializada, três pontuações merecem atenção governamental. A primeira delas está vinculada aos primeiros anos do período de redemocratização do país, com destaque para 1988. É nesse período (1986-1994) que encontramos o maior nível de correlação e de correspondência entre as prioridades dos poderes Executivo, Legislativo e dos indicadores extraídos das conferências nacionais de saúde de 1986 e 1992. A estruturação da política de saúde, as formas de financiamento e de oferta de serviços, a relação entre centralização e descentralização, bem como a universalidade e a compreensão da saúde como um direito do cidadão e obrigação do Estado, aparecem no topo das prioridades sobre a saúde nacional, desde as atas da Conferência Nacional de Saúde de 1986, passando pelas normatizações e até a promulgação da Constituição Federal de 1988. E permanecem assim, com altos índices de atenção, até os anos 1990, conforme mostra a atenção nas mensagens ao Congresso Nacional e nas produções legislativas aprovadas.

Essa alta correlação existente na atenção dos mais diversos atores e locus de produção de imagens de políticas, nos primeiros anos de redemocratização, sinaliza o rompimento com o modelo de política de saúde até então vigente no país, configurando um momento de fortes mudanças no sistema de oferta de serviço. Mais do que isso, a imagem da saúde é redefinida como sendo direito do cidadão e dever do Estado. Essa prioridade, que começa discretamente em 1986 e se acentua em 1988 e 1990, evidencia mudanças significativas na atenção sobre a saúde. A legislação aprovada nesse período, quer seja a própria CF/88 ou a Lei Orgânica da Saúde e a Lei $n^{\circ} 8.142 / 1990$, institucionaliza a mudança sobre a imagem e configuração das políticas de saúde no país.

De acordo com Draibe (2005, p. 17), esse período, identificado como o primeiro ciclo de reformas, foi

impulsionado por forte movimento social, ganhou seus contornos definitivos na Constituição de 1988, com a criação do Sistema Unificado de Saúde (SUS), apoiado no direito universal da população à saúde. A sua implantação, na década de 1990, revelou-se também um processo notável de construção institucional, de criação de capacidades administrativas, gerenciais e de prestação dos serviços de saúde, em todo o país e, especialmente, em suas regiões mais pobres.

As grandes transformações vivenciadas no final dos anos 1980 e início dos anos 1990 dão lugar, nos anos seguintes, a um período de ajustes e de acomodação no subsistema da política de saúde. Assim, os anos 1991 a 1993 são marcados por um novo período incremental, baseado na produção de legislações e normas de menor impacto, mas que alinham e complementam essa nova política de saúde.

Os anos 1993 a 1995 marcam o segundo pico de atenção sobre as políticas de saúde no Brasil. 
A troca de governo com a eleição de Fernando Henrique Cardoso pontua novas prioridades e mudanças na atenção sobre as políticas de saúde. Conforme mostram os dados de mensagens ao Congresso e de legislações aprovadas, no período de 1993 a 1995 ascende à agenda do Executivo e do Legislativo a atenção sobre cuidados primários, prevenção e promoção da saúde e, por fim, sobre cuidados continuados e reabilitação. Esses três tópicos, priorizados pelos atores governamentais nos documentos analisados, apresentam forte relação com as prioridades mapeadas no relatório da Conferência Nacional de Saúde de 1992. Essa priorização resultou na criação, em 1995, do Programa Saúde da Família (PSF), caracterizado por uma estratégia de coordenação nacional e implantação localizada, a partir da atenção básica aos serviços primários de saúde, de promoção e prevenção e de manutenção do atendimento de forma continuada às famílias. Draibe (2005) se remete a esse período como um segundo ciclo de reforma parcial do SUS, envolvendo medidas de diversificação do modelo de assistência e focalização das ações básicas à população carente.

O último pico de atenção sobre as políticas de saúde mostra uma mudança de trajetória importante no período compreendido entre 1997 e 2000 . Essa inflexão está associada à crescente atenção e priorização de sistemas alternativos de saúde, como seguros e planos privados. Crescente nas prioridades mapeadas nas mensagens da presidência da República ao Congresso Nacional desde 1996, com pico em 1997 e 1998, a temática dos planos de saúde é regulamentada com a Lei dos Planos de Saúde (Lei no 9.656/1998). O período, marcado por inúmeros processos de privatização e de redução da atuação direta do Estado, sobretudo na oferta de serviços e com enxugamento do orçamento destinado às políticas sociais, é marcado pelo aumento da atenção e priorização de reformas e alternativas ao sistema de saúde vigente. Também nesse período são priorizadas as regulamentações sobre medicamentos e indústria farmacêutica, sobretudo aquelas vinculadas ao tratamento e à prevenção da aids e de doenças sexualmente transmissíveis, além de acordos de cooperação na oferta de serviços de saúde.

O período seguinte, que tem início em 2000 e segue até o fim desta análise, em 2003, apresenta uma lógica na contramão do que indicava o histórico da saúde no país, com expansão e descentralização no acesso ao SUS. Os dados evidenciam um nítido e forte deslocamento das prioridades dos atores governamentais com declínio da atenção geral sobre a saúde e redução acentuada da correlação entre as prioridades mapeadas na Conferência Nacional de Saúde de 2000 e 2004, com as prioridades dos poderes Executivo e Legislativo na produção legal do mesmo período.

A partir das análises foi possível identificar quais pontos específicos dentro da política de saúde concentraram a atenção dos tomadores de decisão e de que forma isso se traduziu em políticas públicas e novos rumos para a saúde brasileira. Também é possível notar a desproporcionalidade da atuação dos poderes nesse processo de normatização, com destaque para a autonomia de atuação do Poder Executivo, além do papel importante de negociação e antecipação de temas descritos nas mensagens ao Congresso. Apontamos, ainda, a possibilidade de ampliação e de replicabilidade deste estudo, tanto para a expansão do seu período de análise quanto para novos estudos em perspectiva comparada com outras políticas setoriais, ou mesmo sobre a saúde em análise comparada com outros contextos nacionais.

\section{Referências}

ABRANCHES, S. Presidencialismo de coalizão: o dilema institucional brasileiro. Dados, Rio de Janeiro, v. 31. n. 5. p. 5-32, 1988.

BAPTISTA, T. W. F. Análise da produção legislativa em saúde no Congresso Nacional brasileiro (1990-2006). Cadernos de Saúde Pública, Rio de Janeiro, v. 26, n. 1, p. 97-109, 2010.

BAUMGARTNER, F. R.; JONES, B. D. Agendas and instability in American politics. Chicago: University of Chicago Press, 1993.

BAUMGARTNER, F. R.; JONES, B. D. (Ed.). Policy dynamics. Chicago: University of Chicago Press, 2002.

BAUMGARTNER, F. R.; JONES, B. D. The politics of information: problem definition and the course of public policy in America. Chicago: University of Chicago Press, 2015. 
BAUMGARTNER, F. R.; GREEN-PEDERSEN, C.; JONES, B. D. Comparative studies of policy agendas. Journal of European Public Policy, London, v. 13, n. 7, p. 959-974, 2006.

BAUMGARTNER, F. R.; JONES, B. D.; MORTENSEN, P. B. Punctuated equilibrium theory: explaining stability and change in public policymaking. In: SABATIER, P. A.; WEIBLE, C. M. Theories of the policy process. 3. ed. Abington: Westview Press, 2014. p. 59-103.

BAUMGARTNER, F. R.; JONES, B. D.; WILKERSON, J. D. Studying policy dynamics. In: BAUMGARTNER, F. R.; JONES, B. D. (Ed.). Policy dynamics. Chicago: University of Chicago Press, 2002, p. 29-46.

BAUMGARTNER, F. R.; JONES, B. D.; WILKERSON, J. D. Comparative studies of policy dynamics. Comparative Political Studies, Beverly Hills, v. 44, n. 8, p. 947-972, 2011.

BERTOLOZZI, M. R.; GRECO, R. M. As políticas de saúde no Brasil: reconstrução histórica e perspectivas atuais. Revista da Escola de Enfermagem da USP, São Paulo, v. 3o, n. 3, p. 380-398, 1996.

BIASOTO JÚNIOR, G.; SILVA, P. L. B.; DAIN, S. Regulação do setor saúde nas Américas: as relações entre o público e o privado numa abordagem sistêmica. Brasília, DF: Opas, 2006.

CAPELLA, A. C. N.; BRASIL, F. G. A dinâmica das políticas públicas: agendas governamentais em perspectiva comparada. In: ENCONTRO NACIONAL DE ENSINO E PESQUISA DO CAMPO DE PÚBLICAS, 1., 2015, Brasília, DF. Anais... Brasília, DF: Universidade de Brasília, 2015.

CAPELLA, A. C. N.; BRASIL, F. G.; SUDANO, A. D. C. G. P. O estudo da agenda governamental: reflexões metodológicas e indicativos para pesquisas.

In: ENCONTRO ANUAL DA ANPOCS, 39., 2015, Caxambu. Anais... São Paulo: Anpocs, 2015. p. 1-43.

CAPELLA, A. C. N.; SOARES, A. G.; BRASIL, F. G. Pesquisa em políticas públicas no Brasil: um mapeamento da aplicação de modelos internacionais recentes na literatura nacional. In: ENCONTRO DA ABCP, 9., 2014, Brasília, DF. Anais eletrônicos... Brasília, DF: Associação Brasileira de Ciência Política, 2014. Disponível em:

<https://bit.ly/2yEMMjP >. Acesso em: 20 out. 2014.
COBB, R. W.; ELDER, C. D. The politics of agendabuilding: an alternative perspective for modern democratic theory. Journal of Politics, Chicago, v. 33, n. 4, p. 892-915, 1971.

COBB, R. W.; ELDER, C. D. Participation in American politics: the dynamics of agenda building. Boston: Allyn and Bancon, 1972.

COUTO, C. G. Constituição, competição e políticas públicas. Lua Nova, São Paulo, n. 65, p. 95-135, 2005.

DRAIBE, S. M. Ciclos de reformas de políticas públicas em ambiente de consolidação da democracia: a experiência brasileira recente de reforma dos programas sociais. Campinas: Unicamp, 2005.

JOHN, P. The policy agendas project: a review. Journal of European Public Policy, London, v. 13, n. 7, p. 975-986, 2006.

JONES, B. D.; BAUMGARTNER, F. R. The politics of attention: how government prioritizes problems. Chicago: University of Chicago Press, 2005.

KINGDON, J. Agendas, alternatives, and public policies. 3. ed. New York: Harper Collins, 2003.

MACHADO, C. V.; BAPTISTA, T. W. F.; NOGUEIRA, C. O. Políticas de saúde no Brasil nos anos 200o: a agenda federal de prioridades. Cadernos de Saúde Pública, Rio de Janeiro, v. 27, n. 3, p. 521-532, 2011.

RODRIGUES, M. M. A.; ZAULI, E. M. Presidentes e Congresso Nacional no processo decisório da política de saúde no Brasil democrático (1985-1998). Dados, Rio de Janeiro, v. 45, n. 3, p. 387-429, 2002.

SABATIER, P.; JENKINS-SMITH, H. The advocacy coalition framework: assessment, revisions and implications for scholars and practitioners. In: SABATIER, P.; JENKINS-SMITH, H. (Ed.). Policy change and learning: an advocacy coalition approach. Boulder: Westview Press, 1993. p. 211-235.

\section{Contribuição dos autores}

Brasil e Capella conceberam o estudo. Capella coordenou o embasamento teórico. Brasil realizou a coleta e análise estatística dos dados. Ambos os autores contribuíram para a redação do artigo.

Recebido: 02/10/2018

Reapresentado: 02/04/2019

Aprovado: 22/05/2019 